\title{
APPLICATION OF IMMERSIVE VIRTUAL REALITY SYSTEMS IN AN INTERDISCIPLINARY DESIGN STUDIO COURSE
}

\author{
Fadi Castronovo ${ }^{1}$, Danielle Oprean ${ }^{2}$, Yifan $\operatorname{Liu}^{3}$ and John Messner ${ }^{3}$
}

\begin{abstract}
The architectural, engineering, and construction (AEC) industry has been witnessing a recent growth of application of visualization and virtual reality technology for design reviews. As our future generations of designers and engineers enter the industry, they will have to possess the ability to leverage such technology. This study aimed at evaluating the experience of students from an interdisciplinary design studio course, in performing internal design reviews with two different types of display systems. The research aimed at understanding which systems the students found most valuable, immersive, and enjoyable when visualizing their models. The first system utilized was a semi-immersive three screen display system, while the second was a single screen large LCD television system. The participants included five groups, with students from different disciplines, such as architecture and architectural engineering. The groups were randomly split into two tracks and took part in an ABBA experimental procedure. The students' responses were collected through a survey, which was administered after they reviewed their design with each system. Based on the findings, the researchers were able to conclude that the utilized semi-immersive display system promoted the students' sense of immersion, spatial presence, and enjoyment, over their regular collaboration pod using an LCD screen.
\end{abstract}

Keywords: virtual reality, design reviews, immersive projection, engineering education.

\section{INTRODUCTION}

Use of visualization and virtual reality (VR) technology have seen significant growth in the architectural, engineering, and construction (AEC) industry over the past decade. Such adoption of visualizations and VR technology have enabled more effective communication in design reviews, coordinating detailed design, and simulating dynamic operation (Whyte 2003; Liu et al. 2014). With this trend of leveraging visualization continuing to grow in the AEC, for design review, in particular, the researchers were interested in the impact on students in an interdisciplinary design studio. To understand the implications for improving student use of more advanced visualization and VR technology, the researchers needed to establish any differences between standard forms of visualization representation and more advanced VR representation in terms of spatial experiences. The researchers considered the overall impact of different display devices in student's internal design reviews on spatial experiences. The following paper presents background on design

1 Department of Engineering, California State University East Bay, Hayward, PA 94542; Email fadi.castronovo@csueastbay.edu

2 Department of Architecture, The Pennsylvania State University, University Park, PA16802; Email dxo12@psu.edu

3 Department of Architectural Engineering, The Pennsylvania State University, University Park, PA16802; Email yx15209@psu.edu, jmessner@engr.psu.edu 
reviews and assessment of VR experiences for design. The methodological approach to the study is discussed next, including the setup and study format. Results and conclusions will then be discussed for implications towards the use of VR visualization in design education.

\section{BACKGROUND}

\subsection{Design Reviews}

The goal of a design review is to evaluate and critique the developed design. During a design review, the design is evaluated against the requirements of the program, the function of spaces or overall performance to identify the potential possibility of design faults and inefficiencies. A key task of design review is to understand the design. A good representation is, therefore, one that communicates design in a way that is less mentally demanding, and thus allows the design to be evaluated more effectively. By overcoming the cognitive limitations, an appropriate representation of design becomes a powerful aid in enhancing the design review process (Rice 2003). There are many different media used for representing and visualizing the design in a design review. The most commonly seen media used in design reviews is 2 Dimensional (2D) drawings. Previous research shows that architectural drawings have shortcomings because an additional effort is needed to visualize the design, especially for complex buildings and structures (Khemlani et al., 1997). Drawings also do not give a good sense of the size and volume of space, furniture, and equipment. This is mainly because of users have to extrapolate the scale of the drawing to one's internal scale, an accurate translation of which may require significant training. This issue limits reviewers' ability to understand the design as it is intended (Henry and Furness 1993). Besides drawings, physical mockups are sometimes developed for design reviews. However, physical mockups can be costly both in time and money to construct (Shiratuddin 2009). In the past decade, three-dimensional (3D) Building Information Models (BIM) have been widely adopted in the design process. The 3D nature and rich information of BIM models make them a valuable visualization media for design information (Leicht et al. 2009). BIM model has also laid the foundation of using VR in design reviews because the workflow of converting BIM models into VR has been well developed (Liu et al. 2016). With the consumerization of VR technology, VR has naturally become a popular choice for design reviews, because of its ability to bring the reviewers accurate sense of scale, depth, and volume, thus greatly reducing the mental burden of understanding the design (Castronovo et al. 2013; Maldovan and Messner 2006).

\subsection{Assessment in VR and Design}

There has long been interest in establishing what VR can provide for the design fields in the built environment (Kim et al. 2013; Liu et al. 2014). VR presents a way for designers to not only visualize but to experience their projects from a first-person perspective. As Dunston et al. (2007) describe it, VR provides compelling experiences of spatial relationships within designs through interactive means. Such experiences are central to the benefit of using VR for design reviews. In particular, VR allows for designers to gain a sense of presence to more accurately experience human scale visualization (Otto et al. 2005). While the potential benefits of VR for design review activities appears great, however, it has seen little use beyond experimental research (Drettakis et al. 2007). Part of the issue may remain with the assessment of VR and how it affords potential benefits for design. VR use has been measured in numerous ways with two central foci: performance of tasks (efficiency, quality) and experience. It is from this model the 
researchers aimed to understand the role of VR in benefiting design teams. Specifically, building on the model used in Balakrishnan et al. (2012), the researchers aimed to validate the development of spatial presence as a result of using a VR system. Previous research has suggested that increases in spatial presence lead to better comprehension of spatial information (Balakrishnan and Sundar 2011; Zikic 2007; Nikolic 2007). To follow this model, it was important to operationalize the VR system to be used for the design reviews so they could be compared accordingly. The researchers operationalized two different displays by the field of view each afforded the design teams. Additionally, the researchers adapted measures for experience, mainly spatial presence - the perception of being in a simulated space - from the well-known MEC-SPQ questionnaire (Vorderer et al. 2004) and enjoyment (Davis et al. 1992).

\section{Methodology}

The goal of this study was to analyze the user experience of architecture and architectural engineering students while performing actual design reviews. In particular, the research team was interested in comparing the design review experience when using semiimmersive and non-immersive display systems. To tackle the research goal, the team developed and explored the following research questions.

1. How was the students' experience while performing the design review with the provided display systems?

2. Was there a difference in the students' experience based on the system that they used?

3. Was there a difference in the students' experience based on the order with which they performed the design review?

The participants for this study were 19 architectural engineering and 5 architecture students, attending a fourth-year interdisciplinary design studio course at the Pennsylvania State University. The architectural engineering students were pursuing four study options, structural, construction, mechanical, and lighting/electrical. The sample was composed of 5 groups, four with 5 students, and one with 4 students. Each of the 5 groups was composed of students representing each of the aforementioned options, except for the last group of 4 students, which did not have a student from the structural option. All participants gave consent for their data to be used in this study.

\subsection{Apparatus}

\subsubsection{Visualization Systems}

The design reviews studied in this research were conducted in two collaborative, interactive workspaces - an open footprint semi-immersive lab partially surrounding the users (Figure 1(a)) and a collaboration "pod" equipped with an LCD screen (Figure 1(a)). The semi-immersive display system, housed in the Immersive Construction Laboratory (ICon Lab) in the Architectural Engineering Department, has an open footprint space with three stereo-enabled 8 foot by 6 -foot rear-projected screens joined at 135-degree angles (Figure 1(a)). The second system was a collaboration station, or "pod" where the students met to discuss their design for the duration of the semester (Figure 1(b)). Each group had their station, which was housed at the Penn State Stuckeman School of Architecture. The collaboration "pod" included a personal computer, equipped with most common building information modelling packages, a 52" LCD display, which allowed a group to 
collaboratively view a building model, and a high definition webcam for remote collaboration. The "pod" also included a table that could seat up to 7 people. Both display systems allowed users to collaboratively interact with large 3D models and perform virtual walk-throughs in real-time. For the design review in the semi-immersive display system, the research team imported the students' models in the Unity3d game engine. Meanwhile, for the design review process in the collaboration "pod", the students were asked to perform a walkthrough in either Autodesk Revit or Navisworks. The use of different software between the systems was due to the inability of the "pod" system to run the Unity virtual walkthrough. The researchers addresses the difference in software by evaluating the model adequacy in the analysis instrument.

\subsubsection{Survey}

Leveraging previous work presented in the literature review and the team's experience in assessment, the research team developed a survey to measure the students' experience.

The survey aimed at collecting the dependent variables listed in Table 1 . The survey was composed of 30 items. The students were asked to self-report and to express their level of agreement with each of the items on a 6-point Likert Scale to force a choice between one of the two systems. As shown in Table 1, each of the survey items were linked to a dependent variable. For example, the average of the items "I had fun using the system" and "I found the system to be enjoyable" was used as the Enjoyment dependent variable.

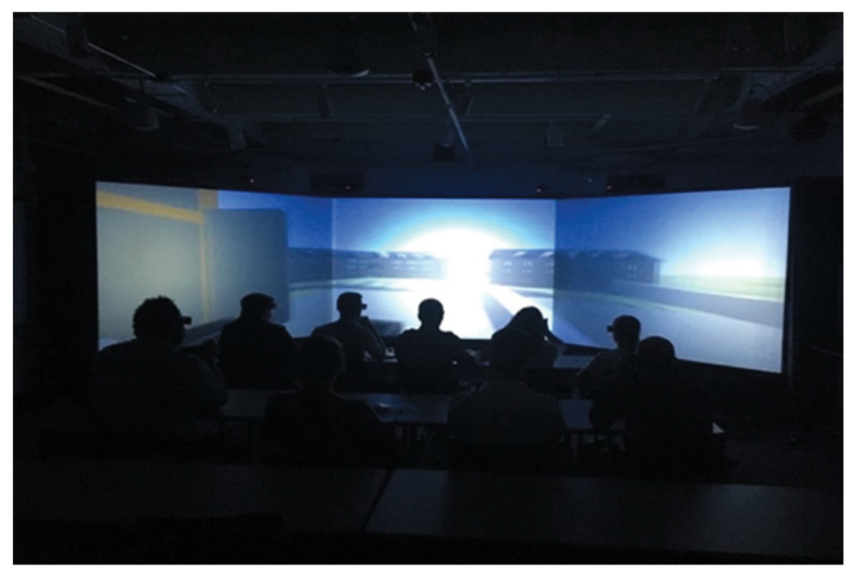

(a)

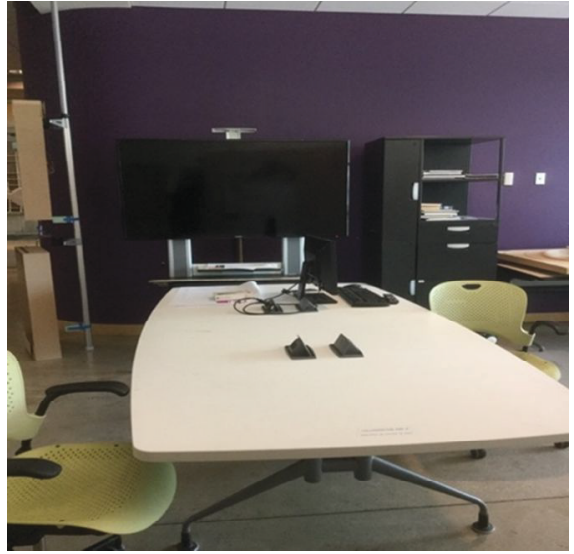

(b)

Figure 1. (a) Semi-immersive display system housed in the ICon lab at Penn State. (b) Collaboration "Pod" with LCD screen housed in the Stuckeman School of Architecture at Penn State

\subsection{Procedure}

To compare users' experience while utilizing the two systems, the student groups were asked to perform design reviews in both systems and rate their experience after using each system. The procedure chosen for this experiment was a balanced quasi-experimental cross-over design (ABBA). With this procedure, 2 groups first used the semi-immersive display system (A) and then the LCD screen (B), while the other 3 groups first used the LCD screen (B) and then the semi-immersive display system (A) (Figure 2). Each treatment was administered on different days, and the duration of each review was limited to 45 minutes. The researchers utilized this experimental design to control for any sequencing or rivalry effects. 
Table 1. Assessment Categories

\begin{tabular}{|c|c|}
\hline Dependent Variable & Survey Item \\
\hline Comfortable Experience & $\begin{array}{l}\text { Overall comfort } \\
\text { Experience }\end{array}$ \\
\hline Model Adequacy & $\begin{array}{c}\text { Model detail } \\
\text { Model realistic } \\
\text { Size of objects }\end{array}$ \\
\hline Review Process & $\begin{array}{c}\text { Viewing of model helped } \\
\text { Confidence of the model } \\
\text { Model overall helpful } \\
\text { Focus }\end{array}$ \\
\hline Immersion & $\begin{array}{c}\text { Screen size } \\
\text { Number of screens }\end{array}$ \\
\hline Enjoyment & $\begin{array}{c}\text { Enjoyable } \\
\text { Fun } \\
\end{array}$ \\
\hline Perceived Usefulness & $\begin{array}{c}\text { Improve performance } \\
\text { Increased productivity } \\
\text { Enhanced effectiveness } \\
\text { Useful }\end{array}$ \\
\hline Use Intention & $\begin{array}{c}\text { Future reviews } \\
\text { Liked using system } \\
\text { Desirable using system }\end{array}$ \\
\hline Spatial Presence & $\begin{array}{c}\text { Moving was realistic } \\
\text { Physically presence } \\
\text { Attention } \\
\text { Part of environment } \\
\text { Do whatever wanted } \\
\text { Take part } \\
\end{array}$ \\
\hline VSI Demographics & $\begin{array}{c}\text { Blueprint } \\
\text { Describe space }\end{array}$ \\
\hline
\end{tabular}

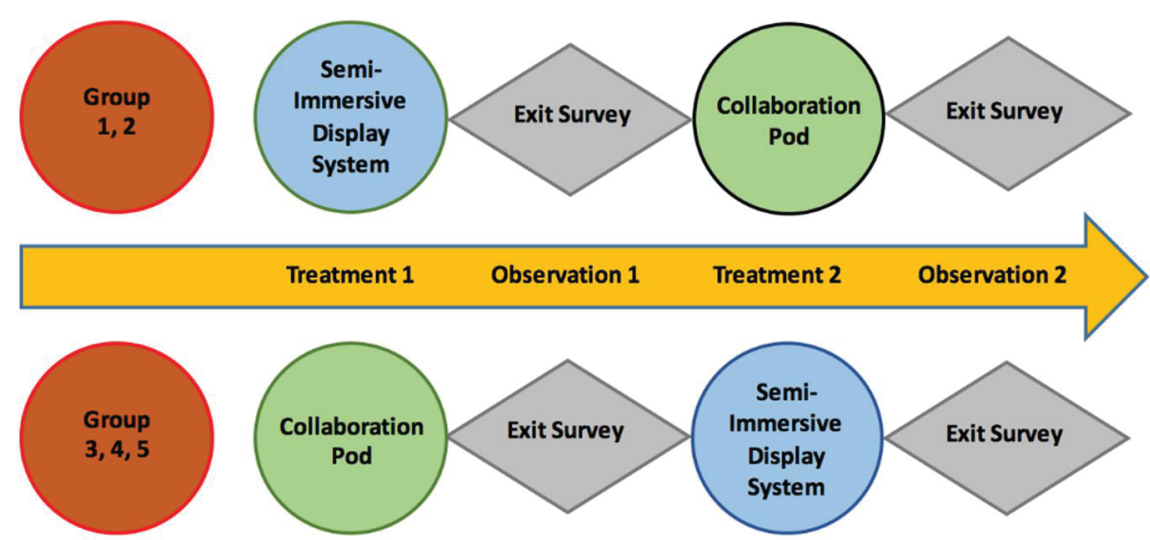

Figure 2. Experimental Procedure

\section{RESULTS AND ANALYSIS}

The three research questions of this study were explored through a series of analyses that directly tested the comparisons of interest. The first question, which aimed at describing the students' experience, was tackled by providing a descriptive analysis of the students' experience. The second research question, which aimed at evaluating the difference in the 
students' experience while using the systems, was tested by performing a Wilcoxon Signed-Rank Test. This test allows one to run non-parametric significance testing for paired-samples. The third research question considered the order with which students utilized the systems. To address the third question, the research team performed a MannWhitney $U$ test. This test allows one to run non-parametric significance testing for independent samples.

Table 2. Descriptive Statistics

\begin{tabular}{cccccccc}
\hline System & Variable & N & Min. & Max. & Mean & $\begin{array}{c}\text { Std. } \\
\text { Deviation }\end{array}$ & Variance \\
\hline & Comfortable & 18 & 2.5 & 6 & 4.61 & 1.01 & 1.02 \\
& Experience & & & & & & \\
& Model Adequacy & 24 & 1.67 & 6 & 4.22 & 1.07 & 1.16 \\
Semi- & Review Process & 24 & 3 & 6 & 4.94 & 0.84 & 0.71 \\
Immersive & Immersion & 24 & 2 & 6 & 4.98 & 0.28 & 0.27 \\
Display & Enjoyment & 24 & 1 & 6 & 4.79 & 0.06 & 0.29 \\
System & Perceived Usefulness & 24 & 1 & 6 & 4.53 & 1.15 & 1.33 \\
& Use Intention & 24 & 1 & 6 & 5 & 0.24 & 1.54 \\
& Spatial Presence & 24 & 2 & 6 & 4.56 & 0.82 & 0.68 \\
& VSI Demographics & 24 & 2.5 & 6 & 4.88 & 0.02 & 1.05 \\
\hline Comfortable & 16 & 3.5 & 6 & 5.03 & 0.83 & 0.68 \\
& Experience & & & & & \\
& Model Adequacy & 22 & 2.33 & 6 & 4.22 & 1.06 & 0.27 \\
Collaboration & Review Process & 24 & 3.75 & 6 & 4.74 & 0.74 & 0.55 \\
Pod & Immersion & 24 & 1 & 6 & 3.42 & 1.40 & 1.95 \\
& Enjoyment & 24 & 2 & 6 & 4.19 & 1.31 & 1.71 \\
& Perceived Usefulness & 24 & 2 & 6 & 4.30 & 1.07 & 0.52 \\
& Use Intention & 24 & 2 & 6 & 4.49 & 1.06 & 0.2 \\
& Spatial Presence & 24 & 1.5 & 6 & 3.33 & 1.40 & 0.95 \\
& VSI Demographics & 24 & 1 & 6 & 4.33 & 0.25 & 1.56 \\
\hline
\end{tabular}

\subsection{Descriptive Data}

The data was analyzed with the SPSS Statistics software package. Based on the responses, 14 students had never been inside the laboratory equipped with the semi-immersive display system. Meanwhile, all of the students used the collaboration pod on a weekly basis during the Spring 2016 semester. The sample size was of 24 students, one of the students' responses was not considered as he was not able to attend all of the review sessions. The participants included 12 female and 12 male students. Also, 19 of the participants were architectural engineering, 5 were in the construction study option, 5 were in the mechanical option, 5 were in the lighting/electrical option, and 4 were in the structural option. The other 5 students were architecture students. The descriptive statistics of the students' responses are presented in Table 2. This table includes means, standard deviations, and variance of the responses. Only 18 students reported their comfort level in the semi-immersive display system and 16 for the collaboration pod. Similarly, for the model adequacy, only 22 students responded. Based on the responses, the semi-immersive display system received a score above 4 on all of the variables. Meanwhile, the 
collaboration pod scored lower than 4 on only immersion and spatial presence. To evaluate the statistical difference between the systems, the team performed a comparison in the following section.

\subsection{Students Experience Based on System}

Leveraging the reported descriptive data, the team tackled the second research question by comparing the student's responses for the systems. A with-in subject analysis was conducted by performing a Wilcoxon Signed-Rank Test. This test compared differences, at a significance level of $\alpha=0.05$, between the students' responses for each of the variables. Table 3 presents the results from the analysis.

Table 3. Wilcoxon Signed Rank Test Results

\begin{tabular}{cc} 
Variable & Significance \\
\hline Comfortable Experience & 0.261 \\
Model Adequacy & 0.57 \\
Review Process & 0.229 \\
Immersion & 0.001 \\
Enjoyment & 0.034 \\
Perceived Usefulness & 0.195 \\
Use Intention & 0.72 \\
Spatial Presence & 0.001 \\
\hline
\end{tabular}

There is statistical evidence that the students found the semi-immersive display system to be more immersive, enjoyable, felt more spatially present. There was no statistical evidence that suggests that the students found either system to be more comfortable, useful, or beneficial for the design review. Similarly, there was no statistical evidence that suggests that there was a difference in the model adequacy in either system.

Table 4. Mann-Whitney U Test Results

\begin{tabular}{cc} 
Variable & Significance \\
\hline Comfortable Experience & 0.259 \\
Model Adequacy & 0.371 \\
Review Process & 0.997 \\
Immersion & 0.625 \\
Enjoyment & 0.138 \\
Perceived Usefulness & 0.371 \\
Use Intention & 0.371 \\
Spatial Presence & 0.048 \\
\hline
\end{tabular}

\subsection{Order Analysis}

Leveraging the reported descriptive data, the team tackled the third research question by comparing the implementation order of the systems. A between-subject analysis was conducted by performing a Mann-Whitney U Test. This test compared differences, at a significance level of $\alpha=0.05$, between the students' responses who performed the design review first in the semi-immersive display system versus the collaboration pod first. Table 
4 presents the results from the analysis. Based on the analysis there is a statistical difference between the groups, suggesting that the students felt a stronger spatial presence if they used the semi-immersive display system first.

\section{CONCLUSIONS AND CONTRIBUTION}

Previous research has looked at the role that immersive technology has when performing design reviews for professional projects or in special design studio courses. With the work presented in this paper, the researchers tackled the role that immersive technology has when performing design reviews in a higher education collaborative design studio course. In particular, the research team was interested in the impact on students' user experiences when performing a design review in a semi-immersive display system, versus a regular LCD screen.

Based on the findings, the researchers were able to conclude that the utilized semiimmersive display system promoted the students' sense of immersion, spatial presence, and enjoyment, over their regular collaboration pod using an LCD screen. According to previous educational research, motivation and enjoyment are key components for the enhancement and support of learning and problem-solving. According to Nikolic (2011) and Castronovo (2016), students are supported in gaining both lower and higher cognitive skills when they enjoy learning with interventions that leverage virtual environments. Therefore, by finding that students' spatial presence, immersion, and enjoyment levels were significantly different using the semi-immersive display than with the pod LCD monitors, it is the researchers' belief the next step would be to evaluate the cognitive skills that students gain and engage in while in an immersive environment. The LCD monitors however appeared useful possibly due to the constant access and level of comfort the students already had with the LCD system. This suggests a longer-term study with students having more access to an immersive system could be beneficial to determining the true value of such large-scale immersive systems. To conclude, future research will aim at evaluating the educational gain of implementing immersive display systems even more in design studio courses, providing more access and allowing students to gain a level of comfort using the technology over the course of a semester.

\section{REFERENCES}

Balakrishnan, B., Oprean, D., Martin, B., \& Smith, M. (2012). Virtual reality: Factors determining spatial presence, comprehension and memory. CONVR 2012, Taiwan.

Balakrishnan, B., and Sundar, S. S. (2011). "Where Am I? How Can I Get There? Impact of Navigability and Narrative Transportation on Spatial Presence." Human-Computer Interaction, 26(3), 161-204.

Castronovo, F. (2016). "Assessing Problem-Solving Skills in Construction Education with the Virtual Construction Simulator.” Penn State University, University Park, PA.

Castronovo, F., Nikolic, D., Liu, Y., and Messner, J. (2013). "An evaluation of immersive virtual reality systems for design reviews.” CONVR 2013, London, UK.

Davis, F.D., Bagozzi, R.P. and Warshaw, P.R. (1992). Extrinsic and intrinsic motivation to use computers in the workplace1. Journal of applied social psychology, 22(14), 11111132.

Drettakis, G., Roussou, M., Reche, A. and Tsingos, N. (2007). "Design and evaluation of a real-world virtual environment for architecture and urban planning." Presence: Teleoperators and Virtual Environments, 16(3), 318-332. 
Dunston, P.S., Arns, L.L., and McGlothlin, J.D. (2007). "An immersive virtual reality mockup for design review of hospital patient rooms." 7th International Conference on Construction Applications of Virtual Reality (CONVR 2007), Penn State University, 139-146.

Henry, D., and Furness, T. (1993). "Spatial Perception in Virtual Environments: Evaluating an Architectural Application." VRAIS '93 Proceedings of the 1993 IEEE Virtual Reality Annual International Symposium, IEEE, Washington, D.C., 33-40.

Khlemani, L., Timerman, A., Benne, B., and Kalay, Y. E. (1997). "Semantically Rich Building Representation." Proceedings of ACADIA '97, Design and Representation, Cincinatti, Ohio.

Kim, Mi Jeong, Xiangyu Wang, Peter ED Love, Heng Li, and Shih-Chung Kang. (2013). "Virtual reality for the built environment: a critical review of recent advances." Journal of Information Technology in Construction (ITcon) 18, no. 14: 279-305.

Leicht, R., Messner, J., and Anumba, C. (2009). "A framework for using interactive workspaces for effective collaboration." ITcon, Special Issue Next Generation Construction IT: Technology Foresight, Future Studies, Roadmapping, and Scenario Planning, 14, 180-203.

Liu, Y., Lather, J., and Messner, J. (2014). "Virtual Reality to Support the Integrated Design Process: A Retrofit Case Study." Computing in Civil and Building Engineering (2014), American Society of Civil Engineers, 801-808.

Liu, Y., Tanujaja, G., Jiang, Z., and Beck, N. (2016). "BIM - Revit to Unity." $<$ https://bim.wikispaces.com/Revit+to+Unity> (Sep. 17, 2016).

Maldovan, K., and Messner, J. I. (2006). "Determining the effects of immersive environments on decision making in the AEC Industry." Joint International Conference on Computing and Decision Making in Civil and Building Engineering, $14-16$.

Nikolic, D. (2007). "Evaluating relative impact of virtual reality components detail and realism on spatial comprehension and presence.” M.S. Thesis, Penn State University, University Park, PA.

Nikolic, D. (2011). "Evaluating a simulation game in construction engineering education: the virtual construction simulator 3.” Penn State University, University Park, PA.

Otto, G., Messner, J.I. and Kalisperis, L. (2005). "Expanding the boundaries of virtual reality for building design and construction." ASCE International Conference on Computing in Civil Engineering, 1-10. doi: 10.1061/40794(179)12

Rice, A. (2003). "Exploring the Impact of Emerging Landscape Visualization Tools on Spatial Perception and Design Education." Trends in Landscape Modeling, E. Buhmann and S. Ervin, eds., Heidelberg: Wichmann, 173-182.

Shiratuddin, M. F. (2009). A Framework for Design Review in a Virtual Environment: Using Context Aware Information Processing. VDM Verlag.

Vorderer, P., Wirth, W., Gouveia, F. R., Biocca, F., Saari, T., Jäncke, L., Böcking, S., Schramm, H., Gysbers, A., and Hartmann, T. (2004). "MEC spatial presence questionnaire (MEC-SPQ): Short documentation and instructions for application.” Report to the European community, Project Presence: MEC (No. IST-2001-37661).

Whyte, J. 2003. "Industrial applications of virtual reality in architecture and construction." Electronic Journal of Information Technology in Construction, 8(Special issue on Virtual Reality Technology in Architecture and Construction), 43-50.

Zikic, N. (2007). "Evaluating Relative Impact of VR Components Screen size, Stereoscopy and Field of View on Spatial Comprehension and Presence in Architecture." M.S. Thesis, The Pennsylvania State University, University Park, PA. 